\title{
Atlas of Pain Management Injection Techniques, Fourth Edition
}

\author{
Steven D. Waldman. Elsevier, St. Louis, Missouri, 2017, \$260 CAD (Hardcover), \\ 712 pages, ISBN: 978-0-323-41415-9
}

\author{
Yaroslava Chtompel, MD (1)
}

Received: 17 December 2016/Accepted: 16 January 2017/Published online: 24 January 2017

(C) Canadian Anesthesiologists' Society 2017

In the fourth edition of Atlas of Pain Management Injection Techniques, Dr. Waldman has created a focused reference text that reads shorter than its 712 pages. The text is divided into eight sections that are conveniently centered on a specific anatomical location of the body. Each section is further broken down into chapters, the total of which is 182. The book is easy to navigate and contains numerous images, including anatomical drawings. An electronic version is also available on and offline, for use on multiple devices.

The text is precisely crafted to provide the information required to perform various injection techniques. Lengthy introductory sections about the use of regional anesthesia or the mechanisms of action of local anesthetics, typically found in many other such texts, are avoided. The author gets straight to the point, clearly presenting each injection in a step-by-step manner. The necessary equipment and medications required are also detailed in the text.

Each chapter is but a few pages long and is focused on a specific pain syndrome, including its symptomatology, targeted physical examination, and associated treatment. The injection techniques presented include both a landmark-based approach as well as one that is performed under ultrasound guidance. Indeed, one major improvement from the previous edition of the book is the inclusion of ultrasound-based techniques for all blocks suited for this approach. This information is a welcome addition, as ultrasound has become a mainstay in an increasing number of pain management procedures. Along

Y. Chtompel, MD (ه)

Department of Anesthesia, McGill University, Montreal, QC, Canada

e-mail: yaroslava.chtompel@mail.mcgill.ca with the textual description, original ultrasound images are included to facilitate and guide application of the technique. In select cases, fluoroscopy-guided approaches are presented as well.

A major strength of the book is the vast array of techniques that are presented. They include musculoskeletal infiltration, such as intra-articular and bursal injections, and peripheral neural blockade. The inclusion of techniques infrequently encountered in daily practice renders this atlas a particularly useful memory aid. A notable shortcoming, however, is that the descriptions of ultrasound-guided techniques are somewhat abridged when compared with other textbooks covering similar material. Thus, the level of detail is inadequate for instructing a novice or a practitioner not already familiar with the technique in question. Another area for improvement would be to offer additional online content in the form of videos and images for the more complex injections. Finally, although the book contains a section on chest wall and trunk injections, no neuraxial or sympathetic blocks are described. For details on those techniques, however, a complementary text, Atlas of Interventional Pain Management, is available by the same author.

In conclusion, Atlas of Pain Management Injection Techniques is a valuable tool for any student or physician involved in pain treatment. The book's excellent organization, use of visual aids, and the author's compact, clear style result in an excellent compendium.

Conflicts of interest No conflicts of interest to disclose.

Editorial responsibility This submission was handled by Dr. Steven Backman, Associate Editor, Canadian Journal of Anesthesia. 